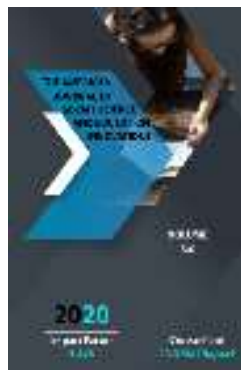

Journal Website: http://usajournalshub.c om/index,php/tajssei

Copyright: Original content from this work may be used under the terms of the creative commons attributes 4.0 licence.

\section{Ecological Education For The Purposes Sustainable Development}

\author{
Olimjon Isomiddinovich Abduganiev \\ Associate Professor, Department Of Geography, Fergana State University, Uzbekistan
}

Gayratjon Zokirovich Abdurakhmanov

Senior Lecturer, Department Of Social Sciences, Fergana Polytechnic Institute, Uzbekistan

\title{
ABSTRACT
}

The article discusses the role of youth education in achieving sustainable development goals. One of the conditions for achieving harmony with nature is ecological literacy of the population. Ecological education should be carried out throughout a person's life. Therefore, the legal framework for the development of ecological education was noted, and recommendations were developed for the formation of environmental awareness in the framework of the educational process for each educational institution.

\section{KEYWORDS}

Biological diversity, protected areas, ecological education, sustainable development, environmental awareness, ecological culture.

\section{INTRODUCTION}

Rapid planetary changes, termed the Great Acceleration, have given human society many benefits. However, we understand that there is a relationship between increased wealth, quality of medicine, nutrition and security and the uneven distribution of these benefits, as well as the deterioration of the natural systems of the Earth. Biodiversity-based nature provides a vast array of opportunities that build modern society like bricks, but nature and biodiversity are disappearing at an alarming rate. Despite the adoption of international agreements such as the Convention on Biological Diversity, we are failing. Current goals and related actions lead, at best, to a controlled reduction in species. To fulfill the plans to combat climate change and introduce the principles of sustainable development, it is necessary to reverse the process of reducing natural resources and biodiversity $[4,5]$. 
One of the most important tools for ensuring environmental protection, rational use of natural resources is raising awareness of all groups of the population through ecological education, which promotes the assimilation of a number of environmental and ethical norms, values, and professional skills that are required to ensure sustainable development. Ecological education consists in the formation of an ecological culture of the individual and society as a set of spiritual experience of human interaction with nature; it is interpreted as a continuous process of self-education and personality development, aimed at the formation and acquisition of special knowledge on environmental protection [1].

\section{MAIN PART}

Within the framework of the National Strategy for Sustainable Development of the Republic of Uzbekistan, the most important priority is "training of personnel, organized as a continuous process that allows for effective management of human resources, involving the involvement of all citizens of Uzbekistan in the process of sustainable development" [1]. In this direction, it is advisable to include the following topics in the composition of specific general professional and special disciplines: issues of general ecology; problems of rational use of resources; social and legal basis for the use of air, land, water, flora and fauna, landscape protection; introduction of innovative ideas in the field of environmental policy of Uzbekistan, international cooperation in the field of ecology and environmental protection, strengthening of environmental, socio-economic, political aspects. For this, the educational and methodological base is an important factor of ecological education, harmoniously combined with the system of continuous education, constantly and effectively contributes to the purposeful and perfect growth of the environmental consciousness of the younger generation [1].

In accordance with it, the Ministries of Public Education and Higher and Secondary Special Education have developed the "Concept of Continuous Ecological Education" and "State Standard of Continuous Ecological Education". The state standard for ecological education has been tested in several general education schools. However, the implementation of this standard has not yet been completed. In the majority of secondary schools of the republic there are no special subjects on ecology, environmental protection. Instead, environmental issues are taught as electives, or integrated into existing academic subjects biology, chemistry, botany, zoology, geography, and others. In preschool institutions, work in this direction is not yet widely carried out $[6,7]$.

By the decree of the Government of Uzbekistan in 2018, the Concept for the Development of Ecological Education was approved. "The goal of the concept is to form ecological knowledge, consciousness and culture among the young generation, improve science in the field of ecology with the involvement of innovative technologies. In preschool educational institutions, the program "Ecologist Child" will be introduced and "Ecological corridors" will be organized. There will also be open-air familiarization hours on Mother Nature. The schools will host the Best Eco-Friendly School and Best Ecological Student contests. The competition "Expert in Ecology" will be organized among students of lyceums and colleges. In higher educational institutions, student dormitories, the activities of "Eco-clubs" will be established. 
Protected natural areas (PNA) are nature conservation, research, and ecological education institutions. Therefore, the main goals of environmental and educational activities on the basis of OPT are: expanding knowledge and ideas about the nature of the native land, about the unique value of natural areas, the development of a careful and responsible attitude to wildlife, involvement in practical research and environmental protection. Each reserve and national park develops its own strategy for conducting ecological education work, relying both on its own ecological educational potential and on real opportunities, taking into account the peculiarities of the protected area and the region in which it is located [8].

The Ministry of Higher and Secondary Specialized Education of the Republic of Uzbekistan is working on training environmental specialists in a number of higher educational institutions. At present, often insufficient attention is paid to family ecological education. The parents of the child should be engaged in ecological education, first of all. It's no secret that one of the main reasons for the deterioration of the ecological situation in Uzbekistan and the depletion of its natural resources is the low level of ecological culture of the population, the formation of which is recognized as a priority direction of the state's activities in the environmental sphere, the most important factor in ensuring environmental safety and sustainable development of the country.

Ecological culture, as a decisive factor in balancing the relationship between society and nature, is becoming more and more relevant now. Ecological education and upbringing are of priority importance in this process, the purpose of which is the purposeful formation of deep and lasting environmental knowledge at all stages of life [7]. The potential of folk traditions in the formation of a value, spiritual, moral, aesthetic attitude to nature, patriotism based on a feeling of kinship with the surrounding landscapes, emotional experience of interaction with nature, the need for direct personal contact with nature, creativity based on nature and labor creative activities aimed at saving it. It is the value, spiritual and moral component of ecological education that requires special attention today, in the context of the reorientation of ecological education from the standpoint of nature management to the standpoint of ecological culture. It is necessary to develop new integrative socioecological projects of upbringing in the family, based on ethno-pedagogical traditions of the development of ethnic groups, including groups living in Central Asia.

The formation of ecological culture, ecological awareness among the population, mainly among children, is a long and difficult process. The main condition in the formation of practical skills for environmentally conscious behavior is the behavior of adults, primarily teachers and parents. In the event that a preschooler observes how elders take care of plants and animals, communicate with each other, behave thoughtfully in nature, he accumulates the appropriate emotional reactions of adults, forms of their behavior, includes this information in the structure of the personality and preserves it for life as the source database. For this reason, ecological education and upbringing should be conducted unobtrusively, without a touch of obligation, but always with pleasure and sincere interest, both for children and adults.

The ecological consciousness of primary schoolchildren is an integrated general cultural indicator of subject learning, the result of highquality teaching and educational work of the school, in the following areas: general cultural, 
educational, cognitive and informational [7, 98 pp.] In addition to ecological education at school, children can get interesting information from extracurricular education - in circles, extracurricular activities, excursions to nature, excursion to production, excursion to scientific laboratories. The solution of environmental problems cannot be ensured by the efforts of only specialists - ecologists. To improve the ecological culture of the population it is necessary:

- To learn to save any natural resources, regardless of whether they are in short supply or not;

- To calculate in advance all the possible consequences of their activities, taking into account not only the obvious, but also the most incredible;

- To change gigantomania for the paradigm of total miniaturization - the search for technologies that minimize energy and material costs; -To get used to paying for something that you personally don't need at all. For example, for waste disposal;

- To fully feel personal responsibility for any violation of the rules of rational nature management $[1,6,7]$.

In one of the latest publications in the scientific journal Nature, scientists analyzed the most serious factors that could lead to the extinction of 8,500 endangered or declining species in the IUCN Red List. They found that overexploitation of natural resources and agriculture continued to be the main causes of declines in biodiversity. Indeed, among all the plants, amphibians, reptiles, birds and mammals that have disappeared since 1500 AD. e., 75\% became extinct precisely because of the negative impact of agricultural activities and overexploitation of natural resources.
In addition to unsustainable agriculture and overexploitation of natural resources, invasive species pose a threat to biodiversity, the spread of which is largely driven by traderelated activities such as the transport of goods. Environmental pollution, such as agricultural waste, and damage from dam building, fires and mining, pose an additional threat $[1,2,7]$.

The subject "Ecology" and "Geoecology" related disciplines are included in all curricula of higher educational institutions of the republic. But this is not enough. Nowadays, real life shows that teaching a subject in a traditional way does not give the desired result. The ecological consciousness of the population is still not at the proper high level. This can be seen in the negative attitude of a part of the population towards the environment. In order to increase the ecological awareness and ecological culture of the population, new learning models should be introduced into education. As part of the educational process for each educational institution, a number of recommendations for the formation of environmental awareness can be offered $[1,6,7]$ :

The environmental learning process must be personally meaningful;

$>$ It is necessary to form ecologically justified stereotypes of behavior, the ability to assess the environment from the standpoint of not only one's own wellbeing, but also the harmony of the relationship "nature - society";

$>$ Introduce a system of scientific knowledge, views and beliefs that ensure the formation of a responsible attitude to the environment in all types of educational activities; 
D Expand cooperation with employees of ecological organizations, nature reserves, national parks;

> Along with national values, to educate students and love for nature.

\section{CONCLUSION}

From now until 2020, when world leaders make key decisions on biodiversity, climate and sustainable development, we have a unique opportunity to strengthen support for the largest project, defining the framework of the program for the conservation of species biodiversity for 2050 and beyond. The main challenge is to reverse the decline in species through a new biodiversity program that could halt ecosystem degradation by 2030 and create positive momentum. This is necessary not only for nature, but also for humans, since addressing the degradation of natural systems is key to achieving the Sustainable Development Goals and the Paris Agreement on Climate by 2030. Therefore, it is urgent to adopt a unified state program on ecological education, which would cover all age groups. It is necessary to integrate environmental knowledge into other academic subjects of the secondary education system, and also it is necessary to introduce the subject "Ecology" as a compulsory subject in all stages of preschool and school education.

\section{REFERENCES}

1. "Concept for the development of environmental education" of the Republic of Uzbekistan. T .., 2018.

2. "National training program" of the Republic of Uzbekistan. T .: 1997.

3. Law of the Republic of Uzbekistan "On Education". T.:. "Uzbekistan", 1997.

4. WWF Report "Living Planet 2018. Strive for More" https://wwf.ru/upload/iblock/2fe/lpr_2018_s ummary_ru.pdf.

5. The 2030 Agenda for Sustainable Development. www.uz.undp. org/content/uzbekistan/ru/

6. Gaibullaeva, M.F.The role of development of environmental education in the Republic of Uzbekistan / M.F. Gaibullaeva, Nodira Abdulazizova. - Text: direct // Young scientist. - 2019. -№ 17 (255). -p. 64-66.

7. Makhkamov B.A. Environmental education of students in the process of labor training // Young scientist. - 2012. - No. 1. T.2. - p. 9799.

8. Meh N.V. Specially protected natural areas as a resource for environmental education. Samarskaya Luka: problems of regional and global ecology. Samarskaya Luka. 2009. - T. 18, No. 2. - p. 221-227. 